\title{
Single-Phase Inverter with Common Grounded Feature and Connected into Grid
}

\author{
Naser Vosoughi Kurdkandi \\ Faculty of Electrical and Computer \\ Engineering \\ University of Tabriz \\ Tabriz, Iran \\ Naser.vosoughi@tabrizu.ac.ir \\ Seyed Hossein Hosseini, \\ Faculty of Electrical and Computer \\ Engineering \\ University of Tabriz \\ Tabriz, Iran \\ Hosseini@tabrizu.ac.ir
}

\author{
Milad Ghavipanjeh Marangalu \\ Faculty of Electrical and Computer \\ Engineering \\ University of Tabriz \\ Tabriz, Iran \\ M.ghavipanjeh@tabrizu.ac.ir \\ Mehran Sabahi \\ Faculty of Electrical and Computer \\ Engineering \\ University of Tabriz \\ Tabriz, Iran \\ Sabahi@tabrizu.ac.ir
}

\author{
Yahya Naderi \\ Department of Electronics and Electrical \\ Engineering \\ University of Strathclyde \\ Glasgow, United Kingdom \\ Yahya.naderi@strath.ac.uk
}

\begin{abstract}
Transformer-less inverters are widely used in gridtied photovoltaic (PV) applications due to their characteristics such as higher efficiency and lower price. In common-ground transformer-less $\mathrm{PV}$ inverters, the neutral point of grid is connected to the negative polarity of the PV panel directly to bypass the parasitic capacitances and to mitigate the leakage current. In this study, a single phase transformer-less grid-tied inverter is proposed and to obtain the unique characteristics of the recommended grid-connected topology, the series-parallel switching technique of the switched capacitor module in a packed unit is applied. Also, by utilizing the common grounding method, the leakage current is eliminated. The provided inverter can generate three-level output voltage waveform. To generate the switching gate pulses of utilized power switches, the peak current controller method is applied. The injected power flows (active and reactive powers) are adjusted using peak current control (PCC) method. Finally, a completely adjusted sinusoidal current can be delivered to power grid. In the next section, the operation procedure, comparison results are presented. Finally, to verify the accurate operation and the theoretical equations of the proposed inverter, simulation results are presented.
\end{abstract}

Keywords - common-ground topology, transformer-less inverter, grid-tied inverter, and switched-capacitor module.

\section{INTRODUCTION}

Transformer-less PV inverters have an important role in gridtied applications [1-3]. The main advantages of these kind of inverters compared with the transformer topologies are affordable price, higher efficiency, and appropriate power density $[4,5]$. Controlling the leakage current injected to the power grid is one of the most important issues in the grid-tied inverters. The variable high frequency common mode voltage (CMV) of the inverter can produce as undesirable leakage current which can be clamped between the null of ac grid and the parasitic capacitor of the negative terminal of PV panel with the value of about $100 \mathrm{nF}$ per $1 \mathrm{KW}[6,7]$. Here, a resonant path is introduced between the output filter inductor and the parasitic capacitor. So that the quality of injected grid current will be bring down and the power losses will be increased. Regarding the above mentioned issues, to reduce the undesirable value of the leakage current, several effective techniques are presented. One of the simplest methods is using the bipolar pulse width modulation (PWM) technique or half-bridge (HB) topologies in lieu of full-bridge (FB) one [7]. In the HB topologies the neutral point is connected to the central point of split capacitors directly. Accordingly, the
CMV is close to half of input voltage [8]. To decrease the unwanted value of leakage current, the common grounded inverts are presented in [1-3]. By connecting the neutral point of power grid to the negative polarity of the PV panel directly, the common mode voltage is clamped to zero. The aim of this study is to propose a new type of single-phase common grounded inverter without using any isolated transforms. Also, it can enhance the efficiency of the proposed inverter by its voltage boosting feature and unipolar PWM technique. Also, through a switched-capacitor module and the virtual dc link method, a two times voltage boosting feature can be achieved without using any additional bulky inductors. To improve the quality of injected grid current and control the active power flow, a peak current controller (PCC) method is applied. This study is organized as: the proposed inverter topology and its operation modes are presented in section II in details. Section III explains the applied PCC strategy in full. Section IV, presents the calculation of utilized circuit components. The comparison of the provided topology with other conventional grid-connected inverters is presented in section V. To confirm the performance of the provided inverter, some simulation results are obtained by Matlab/Simulink software in section VI. Last but not the least, the conclusion of the paper is made in section VII.

\section{PROPOSED TOPOLOGY}

The proposed three-level grid-tied inverter shown in Fig. 1 consists of 6 power switches $\left(S_{1} \sim S_{6}\right), 3$ diodes $\left(D_{1} \sim D_{3}\right)$, and 3 capacitors $\left(C_{1} \sim C_{3}\right)$. This new topology is modulated using single-bound hysteresis technique. Integrating switched-capacitor based module in the structure, the proposed inverter can boost the amplitude of input dc voltage source (PV panel) within a single stage. All of the utilized power switches in this structure are unidirectional. As shown in Fig.1, the negative polarity of the PV panel is connected to the null of the power grid directly. As a result, the provided inverter can be considered as a common grounded topology. To smooth the waveform of output current, an inductor is used as an L-type filter. In the proposed inverter the capacitor $C_{1}$ is charged to $V_{P V}$ and both of the capacitors $C_{2}$ and $C_{3}$ are charged to $2 V_{P V}$. Also, the peak value of the output voltage is equal to $2 V_{P V}$. Assuming the same polarity for current and voltage of the grid, four operation modes can be considered 
for the provided structure. The operation modes of the proposed three-level inverter are described in Fig. 2 (a) (d).

\section{Positive half cycle:}

\section{A) First operation mode}

The equivalent electrical circuit of this operation mode is shown in Fig. 2(a) in which switches $\mathrm{S}_{1}, \mathrm{~S}_{3}, \mathrm{~S}_{5}$ are in ONstate and the power diode $\mathrm{D}_{2}$ is conducting. Here, the capacitor $\mathrm{C}_{1}$ is in series with the input power supply $\left(V_{P V}\right)$. The capacitor $C_{2}$ is charged to $2 V_{\mathrm{PV}}$ trough the input voltage power supply and capacitor $\mathrm{C}_{1}$. Also, the input dc source and capacitor $\mathrm{C}_{1}$ inject the power to the grid which will make the output voltage equal to $2 V_{P V}$.

\section{B) Second operation mode}

The electrical circuit of this mode is depicted in Fig. 2(b). As shown in this figure, the switch $S_{2}$ is in ON-state and capacitor $C_{1}$ is charged to $V_{P V}$. Since in the previous operation mode the capacitor $C_{2}$ was charged to $2 V_{P V}$, the energy of the capacitor $\mathrm{C}_{2}$ is transmitted to capacitor $C_{3}$. So, the capacitor $C_{3}$ is charged to $2 V_{P V}$. In order to generate the zero voltage level, the switches $\mathrm{S}_{2}, \mathrm{~S}_{4}$ and $\mathrm{S}_{5}$ are turned on in this mode. Also, the freewheeling current passes through switches $S_{4}$ and $\mathrm{S}_{5}$.

\section{Negative half cycle:}

\section{C) Third operation mode}

Fig. 2(c) shows the equivalent electrical circuit of this mode. To produce the $-2 \mathrm{~V}_{\mathrm{PV}}$ level at the output voltage waveform, the switches $S_{1}, S_{3}$ and $\mathrm{S}_{6}$ are in $\mathrm{ON}$-state. In this mode, capacitor $\mathrm{C}_{2}$ is charged to $2 \mathrm{~V}_{\mathrm{PV}}$ though the input dc source and capacitors $\mathrm{C}_{1}$.

\section{D) Forth operation mode}

Fig. 2(d) indicates the electrical circuit of this mode. In this mode, the switch $S_{2}$ is turned on and capacitor $C_{1}$ is charged to the input voltage $\left(V_{C 1}=V_{P V}\right)$. The energy of the capacitor $C_{2}$ is transmitted to capacitor $C_{3}$. Therefore, the capacitor $C_{3}$ is charged to $2 V_{P V}$. The freewheeling current passes through switches $\mathrm{S}_{4}$ and $\mathrm{S}_{5}$ which also generates the zero level of the output voltage waveform. It should be noted that during negative half cycle, the power injection into the grid is done by the capacitor $C_{3}$.

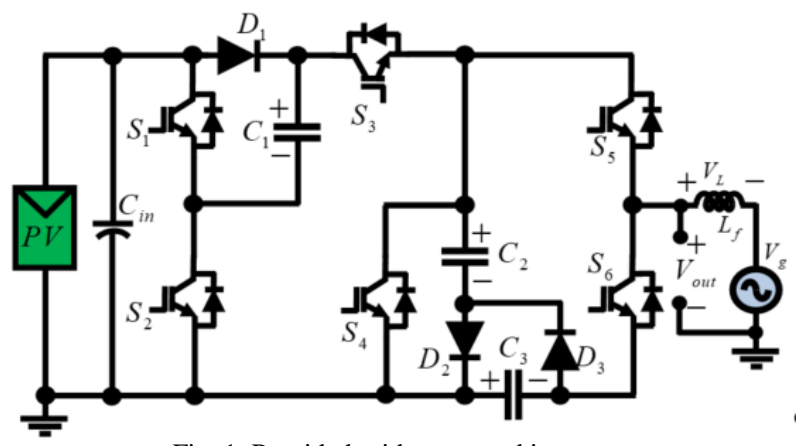

Fig. 1. Provided grid connected inverter.

\section{PEAK CURRENT CONTROL STRATEGY OF THE PROPOSED} GRID-TIED INVERTER

In the provided structure to obtain the switching gate pulses and adjust the injected grid power flows, a peak current control method is applied to the proposed inverter. The suggested controlling technique is depicted in Fig.3. In the provided structure, PV array is assumed as input power supply of the provided inverter. To obtain the maximum output power of PV panel, the maximum power point tracker (MPPT) unit is utilized in the provided control strategy. In order to detect the desired magnitude and phase angle of the grid, a phase locked loop (PLL) unit is required [1-3]. Here, by measuring the voltage and current of the PV panels and using the conventional perturb \& observation $(\mathrm{P} \& \mathrm{O})$ strategy, the maximum power of PV panel is obtained. Therefore, with respect to the required value of injected power flows, the needed phase and amplitude of injected grid current (the current reference $\left.\left(i_{r e f}\right)\right)$ are obtained. The obtained $i_{\text {ref }}$ is delivered to the current controller unit, using which the peak current controller strategy is implemented. Comparing $i_{\text {ref }}$ with the measured injected grid current $\left(i_{g}\right)$, the switching gate pulses of the IGBTs are obtained. The operating of the provided inverter is a function of the polarity of the instantaneous value of the grid voltage $\left(v_{g}\right)$. By allocating a given sampling time $\left(T_{\text {samp }}\right)$, the grid current is compared with the $i_{\text {ref }}$ obtained by the MPPT and PLL units within a $T_{\text {samp }}$. Considering the presented controlling technique, the grid current can follow the sinusoidal waveform of appropriate reference current accurately.

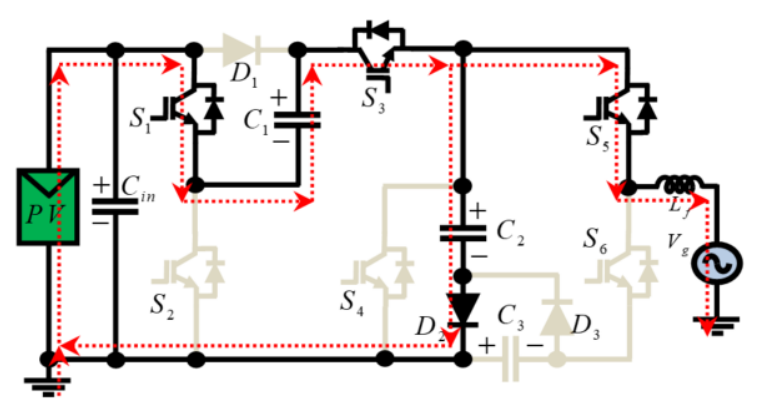

(a)

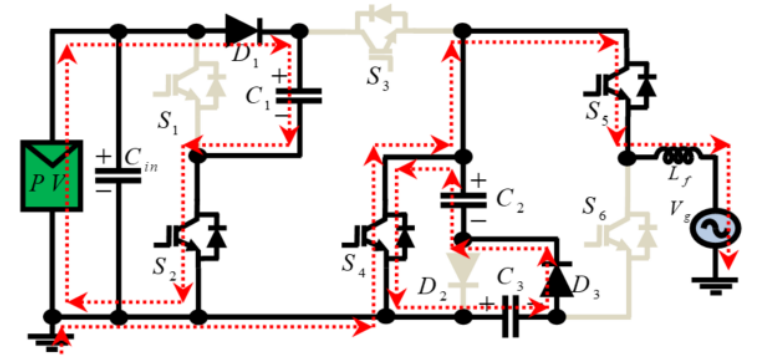

(b)

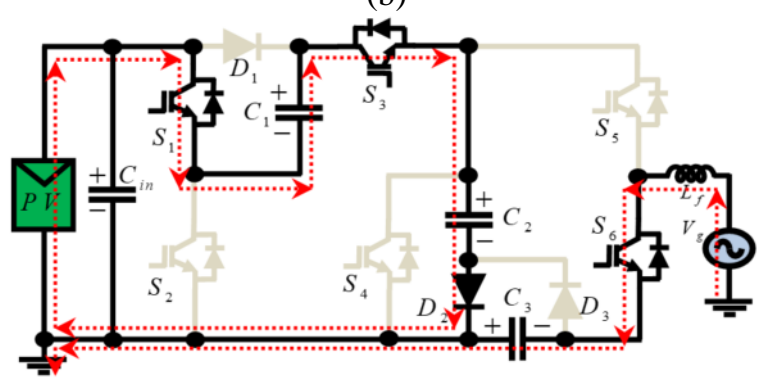

(c) 


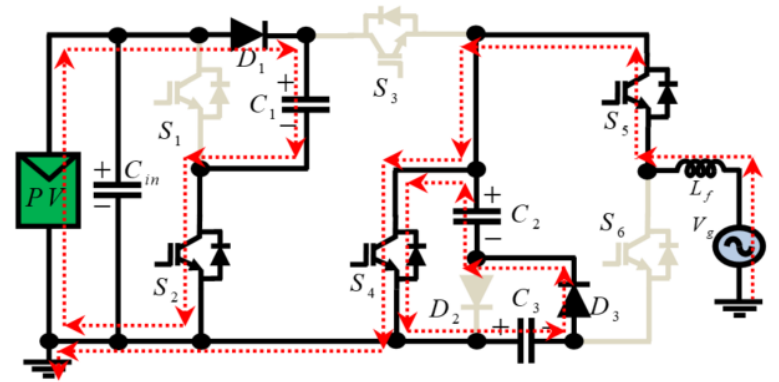

Fig. 2. Operational modes of the provided topology.

(d)

\section{DESIGN GUIDE LINES}

This section of the paper presents the desirable values of the output filter $\left(L_{f}\right)$ and values of utilized capacitors $\left(C_{1} \sim C_{3}\right)$.

\section{A) Calculation of inductance of L-type filter}

The equation of inductor output filter $\left(i_{L f}(t)\right)$ according to its across voltage $\left(V_{L}(t)\right)$ and initial current $\left(i_{L_{f}}(0)\right)$ can be written as;

$i_{L_{f}}(t)=\frac{1}{L_{f}} \int_{0}^{t} V_{L}(t) d t+i_{L_{f}}(0)$

The current ripple of the output filter $\left(L_{f}\right)$ is obtained as;

$\Delta I_{L_{f}}=\frac{\left(V_{\text {out }}-v_{g}\right) \cdot d}{f_{s} \cdot L_{f}}$

Using the inductor volt-second balanced technique for the voltage of the output filter during the full cycle of the switching period, the duty cycle and voltage gain of the proposed topology can be obtained as follows;

$$
\begin{aligned}
& \int_{0}^{d T_{s}}\left(2 V_{P V}-v_{g}\right) d t+\int_{d T_{s}}^{T_{s}}\left(-v_{g}\right)=0 \\
& d=\frac{v_{g}}{2 V_{P V}}=\frac{V_{m, g} \sin \omega t}{2 V_{P V}} \\
& g=\frac{v_{g}}{V_{P V}}=2 d
\end{aligned}
$$

Here, $V_{\text {out }}$ indicates the inverter output voltage. Replacing (4) into (2), the current ripple of output filter can be calculated as follows;

$$
\begin{aligned}
& \Delta I_{L_{f}}=\frac{\left(2 \cdot v_{g} \cdot V_{P V}\right)-v_{g}^{2}}{2 L_{f} \cdot V_{P V}} \cdot T_{s} \\
& T_{s}=2 T_{\text {samp }}
\end{aligned}
$$

Here, the $T_{s}$ and $f_{s}$ denote to time period of switching and switching frequency, respectively. When the grid voltage waveform is at its maximum value $\left(V_{m, g}\right)$, the ripple of inductor current reaches its peak value and can be calculated as follows;

$$
L_{f}=\left(\frac{2 V_{P V} \cdot V_{m, g}-V_{m, g}^{2}}{2 V_{P V} \cdot \Delta I_{L_{f, \max }}}\right) \cdot T_{s}
$$

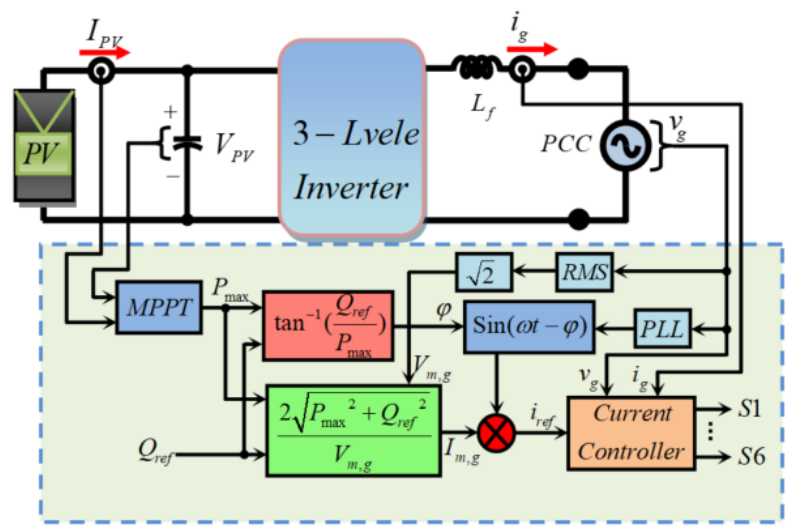

Fig. 3. Controlling system for provided inverter

\section{B) Determination of capacitance of utilized capacitors}

With regard to Fig. 2(a), during the first operation mode, the passing current of capacitor $C_{l}$ is equal to the inductor current. The capacitor voltage is written as follows;

$$
V_{C_{1}}(t)=V_{C_{1}}(0)+\frac{1}{C_{1}} \int_{0}^{t} i_{C_{1}}(t) d t
$$

Moreover, the capacitor $C_{l}$ voltage ripple is calculated as;

$$
\Delta V_{C_{1}}=\left(\frac{i_{L} \cdot v_{g}}{2 V_{P V} \cdot C_{1}}\right) \cdot T_{s}
$$

The maximum value of the voltage ripple of capacitor $\mathrm{C}_{1}$ is obtained when the grid voltage and the injected grid current are at their maximum values. Therefore, the value of $C_{1}$ is calculated as;

$$
C_{1}=\left(\frac{\mathrm{I}_{\mathrm{m}, g} \times V_{m, g}}{2 \Delta V_{C_{1}, \max } \times V_{P V}}\right) \cdot T_{s}
$$

By replacing the average values of grid voltage and current of output inductor filter during the half cycle of grid voltage waveform, the accurate value of capacitor $C_{1}$ can be written as;

$$
\begin{gathered}
C_{1}=\left(\frac{4 \mathrm{I}_{\mathrm{m}, g} \times V_{m, g}}{2 \Delta V_{C_{1}} \times V_{P V}}\right) \cdot \frac{T_{s}}{\pi^{2}} \\
\text { V. COMPARISON RESULTS }
\end{gathered}
$$

In this section to highlight the advantages of the suggested structure, the proposed grid-tied inverter is compared with other recently proposed grid-connected topologies. The summary of this comparison is presented in Table I. Hereon, number of all the utilized elements containing active and passive components besides some specifications such as voltage boosting capability, type of pulse width modulation (PWM) of inverters, number of ON-state power switches per each instant of the switching frequency, and the measured leakage current in different structures have been compared. With respect to Table I, none of the compared structures have step-up voltage feature. However, the proposed topology can increase the input voltage without any extra boosting stage. Considering Table I, the topologies cannot totally repress the generated leakage current whereas, the proposed inverter can eliminated the leakage current completely. It can be concluded that, the proposed topology is a suitable topology for grid-tied PV applications. 
Table I. comparison of the proposed inverter with some other grid-tied inverters

\begin{tabular}{|c|c|c|c|c|c|c|c|}
\hline topology & $\begin{array}{c}\text { NO. of } \\
\text { switches }\end{array}$ & $\begin{array}{c}\text { NO. of } \\
\text { diodes }\end{array}$ & $\begin{array}{c}\text { NO. of } \\
\text { capacitors }\end{array}$ & $\begin{array}{c}\text { NO. of } \\
\text { inductors }\left(\boldsymbol{L}_{\boldsymbol{f}}\right)\end{array}$ & $\begin{array}{c}\text { PWM } \\
\text { modulation }\end{array}$ & $\begin{array}{c}\text { Boosting } \\
\text { capability }\end{array}$ & $\begin{array}{c}\text { leakage } \\
\text { current }\end{array}$ \\
\hline H6 [9, 10] & 6 & 2 & 1 & 2 & unipolar & NO & $46 \mathrm{~mA}$ \\
\hline HERIC & 5 & 2 & - & 2 & unipolar & NO & $83 \mathrm{~mA}$ \\
\hline OH5 [11] & 6 & - & 1 & 2 & unipolar & NO & $45 \mathrm{~mA}$ \\
\hline H5 & 5 & - & - & 2 & unipolar & NO & $88 \mathrm{~mA}$ \\
\hline HB-ZVRB [12] & 5 & 5 & 1 & 1 & unipolar & NO & $28 \mathrm{~mA}$ \\
\hline proposed & 6 & 3 & 3 & 1 & unipolar & YES & About zero \\
\hline
\end{tabular}

\section{SimULATION RESULTS}

The simulation analysis of the 3-level grid-tied inverter is carried out utilizing Matlab/Simulink. The value of the capacitors $C_{1}, C_{2}$, and $C_{3}$ are equal to $220 \mu F, 560 \mu \mathrm{F}$, and $560 \mu F$ respectively. Also, the value of the input power dc supply has been assumed $200 \mathrm{~V}$. The inductance of filter inductor is about $3 \mathrm{mH}$. The inverter output voltage with peak value of $400 \mathrm{~V}$ and sinusoidal injected current at unity $(\mathrm{PF}=1)$, leading and lagging power factors are depicted in Fig. 4(a), (b) and (c), respectively. So, it is validated that the provided system has the ability of tracking the reference current through the output filter. It is confirmed that proposed structure and its corresponding peak current control strategy could work together suitably. Using common grounding removes the leakage current. It can be seen that the voltage across of capacitors $C_{1}, C_{2}$, and $C_{3}$ have been adjusted to $200 \mathrm{~V}, 400 \mathrm{~V}$

and $400 \mathrm{~V}$, respectively. Also, the voltage ripple of the capacitors is within an acceptable range. The suggested gridtied inverter also has the capability to control the reactive power. Therefore, under different conditions of power factor (PF) the injected current to grid and voltage of grid are indicated in Fig.6. It is shown that, the presented grid-tied inverter using the peak current control strategy can inject the sinusoidal waveform of current under different conditions of desirable PF. The grid voltage and injected current under the unity, leading and lagging power factors are depicted in Fig. 6 (a), (b) and (c), respectively. With respect to this figure, the value of injected power to the grid is equal to $0.77 \mathrm{KW}$. In addition, the voltage stress on some of the utilized power switches $\left(\mathrm{S}_{3} \sim \mathrm{S}_{6}\right)$ are presented in Fig. 7 (a)-(d). In this figure, the standing voltage of switch $S_{3}$ and $S_{4}$ are equal to $400 \mathrm{~V}$ and standing voltage of switches S5 and S6 are about $800 \mathrm{~V}$. Finally, with regard to obtained simulation results, the accurate performance of the suggested is confirmed.

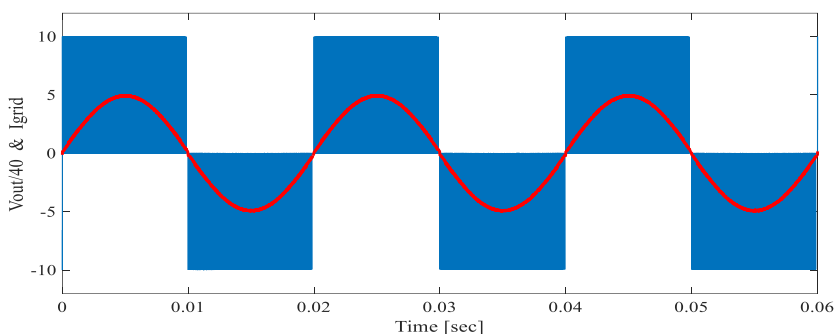

(a)

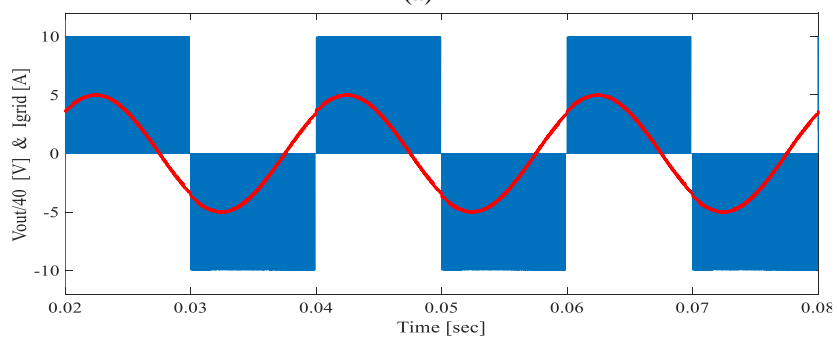

(b)

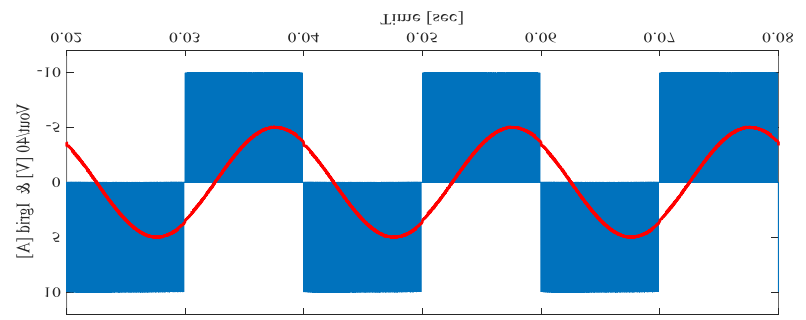

(c)

Fig. 4. Simulation results of inverter output voltage and the injected current to grid under different PFs (a) unity PF (b) leading PF (c) lagging PF.

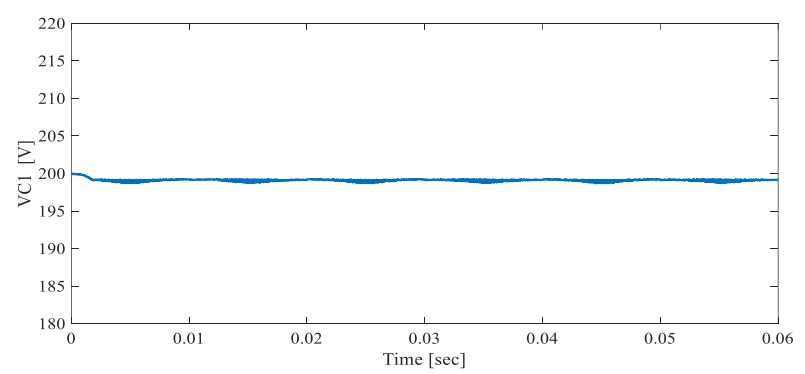

(a)

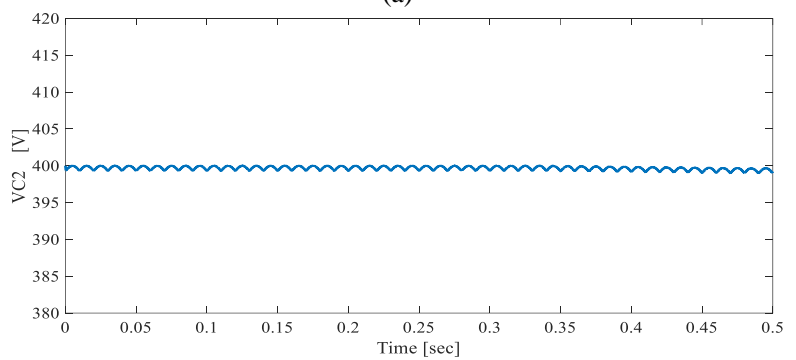

(b)

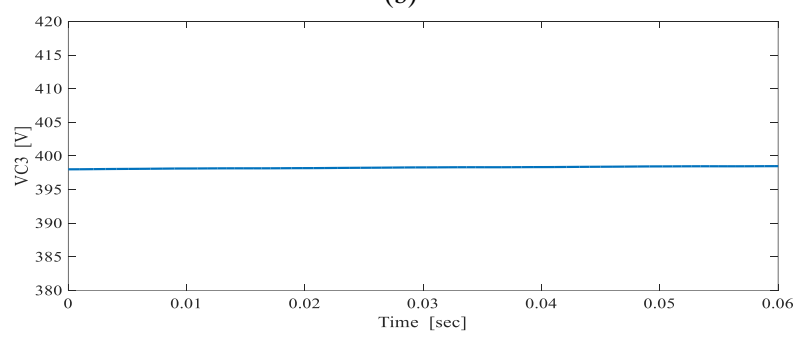

(c)

Fig. 5. Across voltage of capacitors (a) $C_{1}$ (b) $C_{2}$ (c) $C_{3}$.

\section{CONCLUSION}

In this paper, a new single phase 3-level grid-tied inverter is proposed. The Suggested inverter proposes the voltage boosting and common grounded characteristics. In order to control the charging and discharging of the capacitors in the switched-capacitor module, series-parallel switching method has been applied. Also, the proposed topology can provide a boosting feature within a single stage process. In this paper, to inject current to grid with high quality and control the active power flow, the PCC method is applied. With respect to this method, a sinusoidal current can be injected to the power grid under different values of PFs. Since the negative polarity of the PV panel is connected directly to the null of ac power grid, the leakage current is eliminated completely. 
Design considerations have also been included in this paper. The provided structure is compared with other conventional grid-connected inverters in the literature. Finally, to confirm the accurate operation of the inverter and the mathematical equations, simulation results based on Matlab/Simulink software are provided.

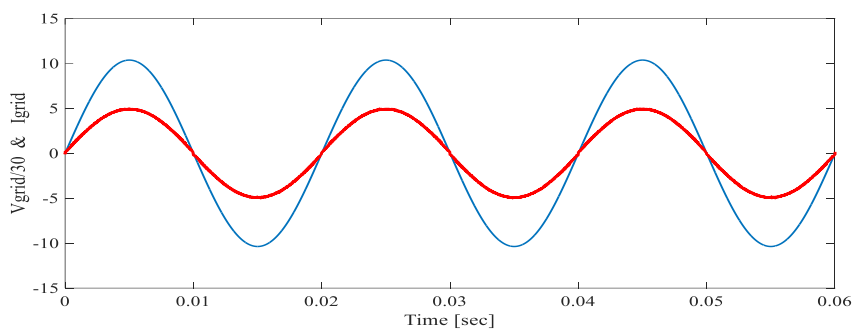

(a)

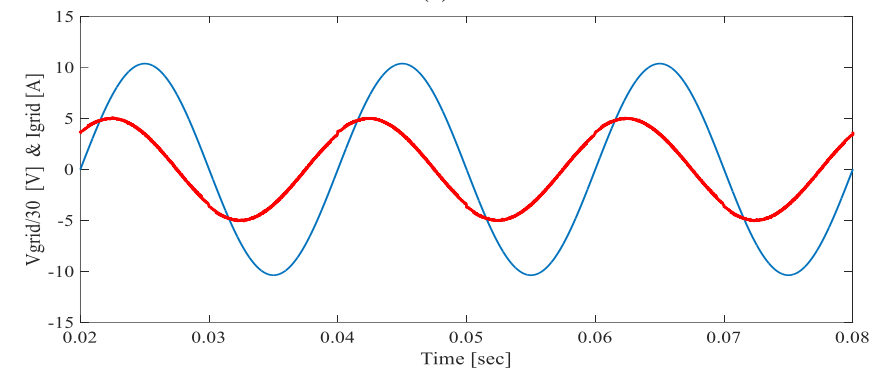

(b)

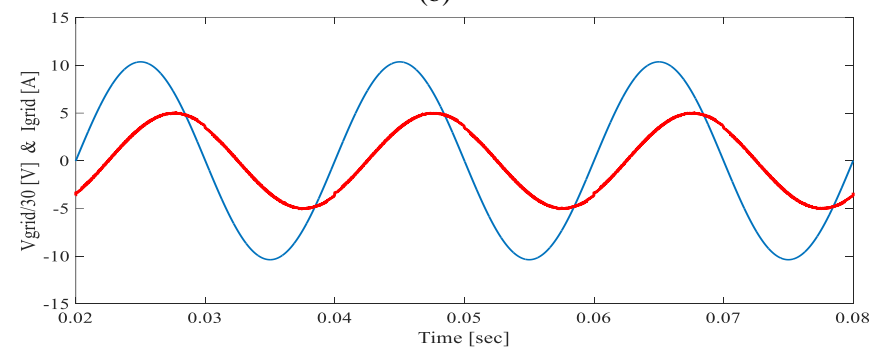

(c)

Fig. 6. The voltage and current of grid (a) unity PF (b) leading PF (c) lagging $\mathrm{PF}$.

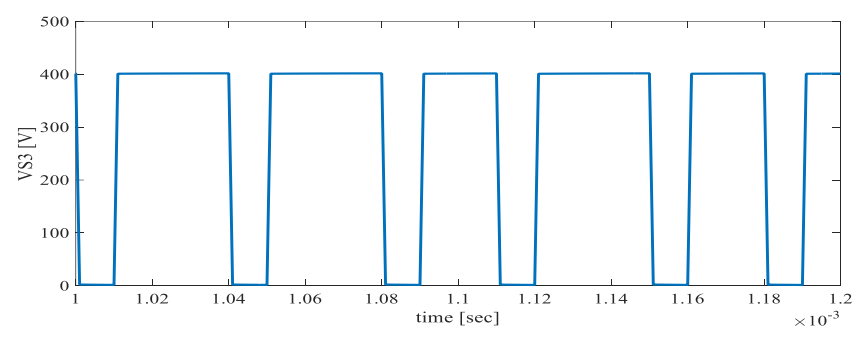

(a)

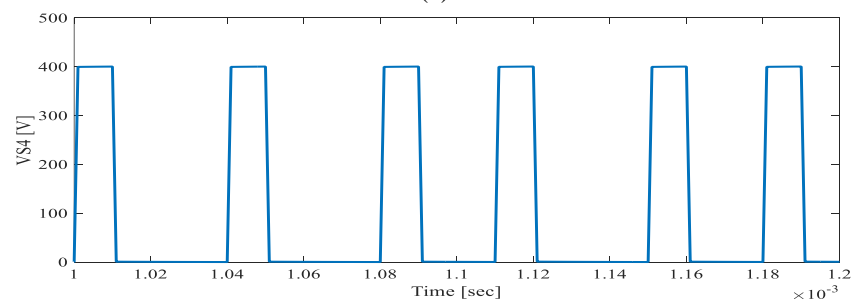

(b)

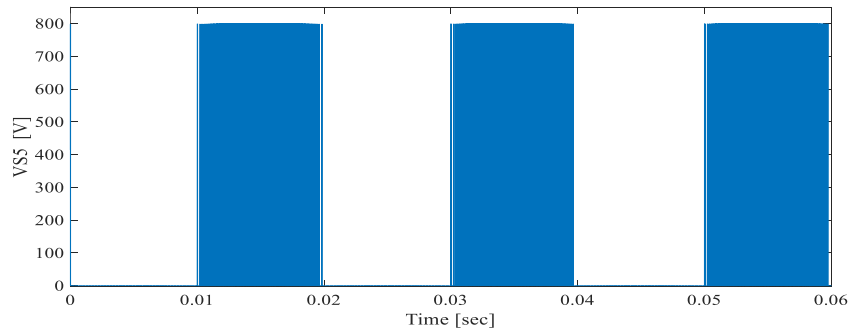

(c)

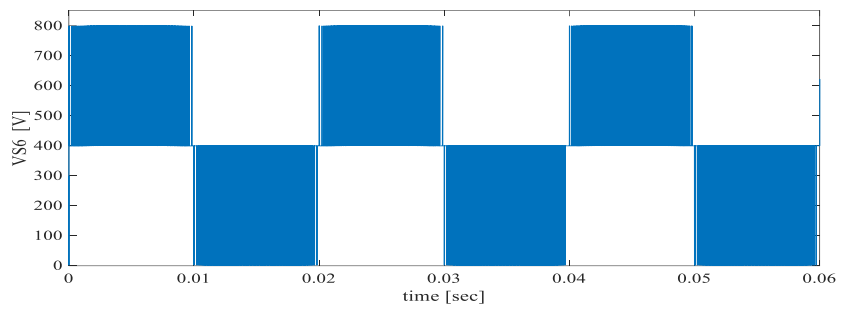

(d)

Fig. 7. The voltage waveform across the utilized power switches (a) $V_{S 3}$ (b) $\mathrm{V}_{\mathrm{S} 4}(\mathrm{c}) \mathrm{V}_{\mathrm{S} 5}(\mathrm{~d}) \mathrm{V}_{\mathrm{S} 6}$.

\section{REFERENCES}

[1] N. Vosoughi, S. H. Hosseini, and M. Sabahi, "Singlephase common-grounded transformer-less grid-tied inverter for PV application," IET Power Electronics, vol. 13, no. 1, pp. 157-167, 2019

[2] N. Vosoughi, S. H. Hosseini, and M. Sabahi, "A New Single Phase Transformerless Grid Connected Inverter with Boosting Ability and Common Ground Feature," IEEE Transactions on Industrial Electronics, 2019.

[3] N. Vosoughi, S. Hosseini, and M. Sabahi, "A New Transformer-less Five-level Grid-Tied Inverter for Photovoltaic Applications," IEEE Transactions on Energy Conversion, 2019.

[4] M. Farhadi-Kangarlu and M. G. Marangalu, "Five-Level Single-DC Source Inverter with Adjustable DC-Link Voltage," in Electrical Engineering (ICEE), Iranian Conference on, 2018, pp. 1017-1021: IEEE.

[5] M. Farhadi-Kangarlu and M. G. Marangalu, "A Single DC-Source Five-Level Inverter Applied in Stand-Alone Photovoltaic Systems Considering MPPT Capability," in 2019 10th International Power Electronics, Drive Systems and Technologies Conference (PEDSTC), 2019, pp. 338-342: IEEE.

[6] O. Lopez et al., "Eliminating ground current in a transformerless photovoltaic application," IEEE transactions on energy conversion, vol. 25 , no. 1, pp. 140-147, 2010.

[7] D. Barater, E. Lorenzani, C. Concari, G. Franceschini, and G. Buticchi, "Recent advances in single-phase transformerless photovoltaic inverters," IET Renewable Power Generation, vol. 10, no. 2, pp. 260-273, 2016.

[8] W. Li, Y. Gu, H. Luo, W. Cui, X. He, and C. Xia, "Topology review and derivation methodology of singlephase transformerless photovoltaic inverters for leakage current suppression," IEEE Transactions on Industrial Electronics, vol. 62, no. 7, pp. 4537-4551, 2015.

[9] B. Ji, J. Wang, and J. Zhao, "High-efficiency singlephase transformerless PV H6 inverter with hybrid modulation method," IEEE Transactions on Industrial Electronics, vol. 60, no. 5, pp. 2104-2115, 2012.

[10] B. Yang, W. Li, Y. Gu, W. Cui, and X. He, "Improved transformerless inverter with common-mode leakage current elimination for a photovoltaic grid-connected power system," IEEE transactions on power electronics, vol. 27, no. 2, pp. 752-762, 2011.

[11] H. Xiao, S. Xie, Y. Chen, and R. Huang, "An optimized transformerless photovoltaic grid-connected inverter," IEEE Transactions on Industrial Electronics, vol. 58, no. 5, pp. 1887-1895, 2010.

[12] T. Kerekes, R. Teodorescu, P. Rodríguez, G. Vázquez, and E. Aldabas, "A new high-efficiency single-phase transformerless PV inverter topology," IEEE

Transactions on industrial electronics, vol. 58, no. 1, pp. 184-191, 2009. 